\title{
Nossas palavras e as deles: \\ o oficio do historiador na atualidade
}

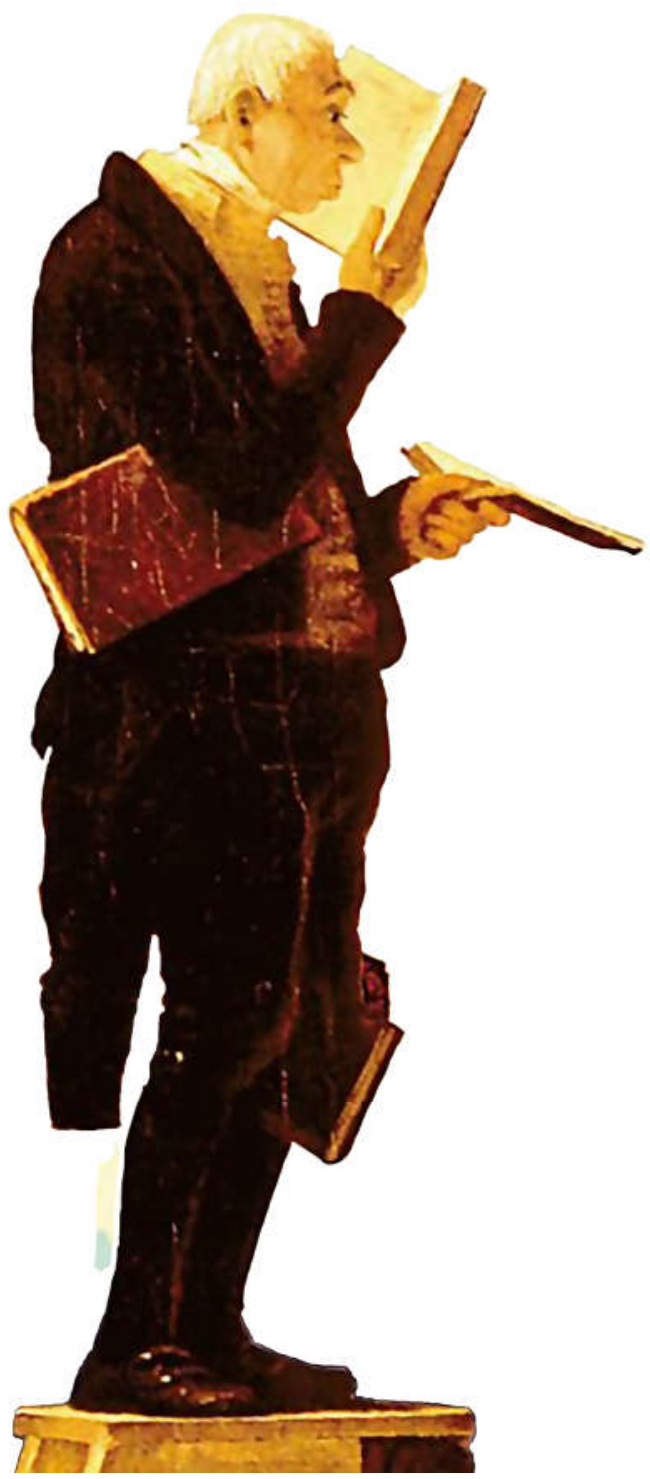

\section{Carlo Ginzburg}

Doutor em Filosofia pela Università di Pisa. Professor de História Cultural Europeia da Scuola Normale Superiore di Pisa (SNS)/Itália. Autor, entre outros livros, de Medo, reverência, terror. São Paulo: Companhia das Letras, 2014.

ginzburg@history.ucla.edu 


\title{
Nossas palavras e as deles: o ofício do historiador na atualidade*
}

Our words, and theirs: a reflection on the Historian's craft, today

\section{Carlo Ginzburg}

\author{
Tradução: Afranio Pedro Martins Neto* \\ Revisão técnica da tradução: Adalberto Paranhos ${ }^{* * *}$
}

\begin{abstract}
\&o
C'est que la chimie avait le grand avantage de s'adresser à

des réalités incapables, par nature, de se nommer elles-mêmes.

Marc Bloch
\end{abstract}

Em suas reflexões metodológicas, publicadas postumamente como Apologie pour l'histoire ou métier d'historien ("O ofício do historiador ou introdução à História"), Marc Bloch observou: "Para grande desespero dos historiadores, os homens não mudam seu vocabulário cada vez que mudam seus costumes". ${ }^{1}$

O resultado dessa divergência é a ambiguidade semântica. Tomemos uma palavra fundamental em nosso vocabulário intelectual e emocional - "liberdade", cujos múltiplos significados estiveram por muito tempo no centro das preocupações de Bloch. Um olhar mais atento para eles lançará alguma luz sobre sua referência ironicamente enfática ao "desespero" dos historiadores, vis-à-vis a lacuna entre a resiliência das palavras e sua mudança de signifi-

\footnotetext{
* Diferentes versões deste artigo foram apresentadas em Roma (Università della Sapienza), Be'er Sheva (Ben-Gurion University), em Los Angeles (Departamento de História, UCLA), Berlim (Freie Universität). Muito obrigado a Andrea Ginzburg, Christopher Ligota, Perry Anderson e, especialmente, Simona Cerutti, por suas críticas, e a Sam Gilbert e Henry Monaco, por sua revisão linguística. A versão aqui publicada figurou em FELLMAN, Susanna and RAHIKAINEN, Marjatta (eds.). Historical knowledge: in quest of theory, method and evidence. Cambridge: Cambridge Scholars Publishing, 2012, p. 97-119. Nota da editoria: excepcionalmente, em respeito ao formato original deste texto, não foram, em geral, seguidas as normas de publicação de ArtCultura.

** Graduado em Letras-Inglês pela Universidade Federal de Goiás (UFG)-Jataí e professor da AB Language School, de Jataí. afraniobilkenvich@gmail.com

*** Doutor em História pela Pontifícia Universidade Católica de São Paulo (PUC-SP). Professor do Programa de Pós-graduação em História da Universidade Federal de Uberlândia (UFU). Pesquisador do CNPq. Autor, entre outros livros, de O roubo da fala: origens da ideologia do trabalhismo no Brasil. 2. ed. São Paulo: Boitempo, 2007. akparanhos@uol.com.br

${ }^{1}$ Bloch, The historian's craft, 34; “Car, au grand désespoir des historiens, les hommes n'ont pas coutume, chaque fois qu'ils changent de mœurs, de changer de vocabulaire". Bloch, "Apologie pour l'histoire", 872. Esta passagem foi trazida novamente à minha atenção por Ciafaloni, "Le domande di Vittorio. Un ricordo di Vittorio Foa", 42.
} 
cado. Bloch mencionou "historiadores", pensando em si mesmo, mas suas reações pessoais tinham raízes mais distantes, bem como mais complexas.

\section{II}

"História”, do grego historìa, é outra palavra de nosso vocabulário que, traduzida em várias línguas, permaneceu a mesma ao longo de vinte e cinco séculos, mas mudou de significado. ${ }^{2}$ Depois de ser usada por médicos, anatomistas, botânicos e antiquários em um sentido que incluía tanto "descrição" quanto "investigação", a história foi referida quase exclusivamente ao domínio da ação humana - embora um traço de seu uso anterior possa ser detectado nas expressões como a "história clínica" de um paciente. Esse estreitamento de seu significado é um efeito colateral de um ponto de inflexão que pode, simbolicamente, ser identificado nesta famosa passagem do texto $O$ ensaiador, de Galileu:

A filosofia está escrita neste vasto livro, que permanece continuamente aberto diante de nossos olhos (quero dizer, o universo). Mas não pode ser entendido a menos que você primeiro tenha aprendido a entender o idioma e reconhecer os caracteres nos quais está escrito. Foi escrito na linguagem da matemática, e os caracteres são triângulos, círculos e outras figuras geométricas. Sem esses meios, é impossível para nós, humanos, entender uma palavra dele.... ${ }^{3}$

Galileu, apesar de suas ligações estreitas com cientistas comprometidos com uma abordagem não matemática do estudo da natureza, anunciou que a linguagem da natureza é - ou estava destinada a se tornar - a linguagem da matemática. ${ }^{4}$ Por uma ótica oposta, a linguagem da história foi, e sempre foi, desde o tempo de Heródoto em diante, uma linguagem humana: sendo, na verdade, a linguagem da vida cotidiana, mesmo quando apoiada em estatísticas e diagramas. ${ }^{5} \mathrm{E}$ a evidência em que o historiador se baseia também está escrita principalmente nessa linguagem da vida cotidiana.

Bloch refletiu intensamente sobre essa contiguidade e suas implicações. Em outra seção de suas reflexões póstumas, o autor afirma que "a história recebe seu vocabulário, na maior parte, do próprio objeto de estudo. Aceita-o, já gasto e deformado pelo uso prolongado; frequentemente, além disso, ambíguo desde o início, como qualquer sistema de expressão que não tenha derivado dos esforços rigorosamente organizados de especialistas técnicos". ${ }^{6}$ Assim, os historiadores se deparam com duas alternativas: ou ecoar a terminologia usada em suas evidências, ou usar uma terminologia que é estranha a

\footnotetext{
2 Pomata e Siraisi (eds.), Historia: empiricism and erudition in Early Modern Europe.

${ }^{3}$ Galilei, Il Saggiatore, 264: “... la filosofia è scritta in questo grandissimo libro che continuamente ci sta aperto dinanzi agli occhi (io dico l'universo), ma non si può intendere se prima non s'impara a intender la lingua, e conoscere i caratteri ne' quali è scritto. Egli è scritto in lingua matematica, e i caratteri son triangoli, cerchi, ed altre figure geometriche, senza i quali mezzi è impossibile a intenderne umanamente parola...". Aqui desenvolvo a interpretação previamente usada em Ginzburg, "Spie: radici di un paradigma indiziario", 172 e 173, e em Ginzburg, “Clues: roots of an evidential paradigm”, esp. 107 e 108.

${ }^{4}$ Freedberg, The eye of the Lynx: Galileo, his friends, and the beginnings of Modern Natural History.

5 Ginzburg, "Spuren einer Paradigmengabelung: Machiavelli, Galilei und die Zensur der Gegenreformation".

${ }^{6}$ Bloch, The historian's craft, 158; Bloch, "Apologie pour 1'histoire", 959.
} 
eles. A primeira alternativa, observa Bloch, não leva a lugar nenhum: às vezes, a resiliência de palavras intrinsecamente ambíguas oculta a mudança em seus significados; em outras, significados semelhantes são ocultados por uma multiplicidade de termos. Ficamos com a outra alternativa, que é arriscada: termos como "sistema de fábrica", por exemplo, podem parecer um substituto para a análise, promovendo assim "anacronismo: o mais imperdoável dos pecados em uma ciência do tempo".7 Apenas as trocas acadêmicas, conclui Bloch, acabarão por levar à construção de um vocabulário comum das ciências humanas; mas inventar novas palavras é preferível a uma projeção tácita de novos significados dentro de termos comumente usados. ${ }^{8}$

Consequentemente, um vocabulário rigoroso pode permitir que a história lide com sua fraqueza intrínseca - a linguagem cotidiana que ela compartilha com a maioria de suas evidências. A referência à terminologia artificial da química, que surge repetidamente nas páginas de Bloch, é reveladora o suficiente: raramente ele esteve tão perto do positivismo. Mas Claude Bernard, em um dos textos clássicos do positivismo, Introduction à la médecine expérimentale (1865) - um livro que Bloch mencionou com alguma discordância - notou, em um parágrafo intitulado "A crítica experimental deve olhar para os fatos, não para as palavras", que essa ambiguidade também ameaça as linguagens convencionais da ciência:

Quando criamos uma palavra para caracterizar um fenômeno, concordamos em geral sobre a ideia que desejamos que ela expresse e o significado preciso que estamos dando a ela; mas com o progresso posterior da ciência, o significado da palavra muda para algumas pessoas, enquanto para outras a palavra permanece na língua com seu significado original. O resultado geralmente é tal discórdia que os homens que usam a mesma palavra expressam ideias muito diferentes. Nossa linguagem, na verdade, é apenas aproximada e mesmo na ciência é tão indefinida que, se perdermos de vista os fenômenos e nos agarrarmos às palavras, sairemos rapidamente da realidade. ${ }^{9}$

\section{III}

Mas o que é, da perspectiva do historiador, a relação entre palavras as palavras da evidência - e realidade? Na resposta de Bloch a esta pergunta, podem-se detectar muitos elementos interligados. Em primeiro lugar, uma sensação de inadequação das palavras face ao que as gera: paixões, sentimentos, pensamentos, necessidades. Bloch exemplifica essa inadequação evocando um caso extremo:

\footnotetext{
${ }^{7}$ Bloch, The historian's craft, 173; “... il fomente l'anachronisme: entre tous les péchés, au regard d'une science du temps, le plus impardonnable ..." Bloch, "Apologie pour l'histoire", 969.

${ }^{8}$ Bloch, The historian's craft, 176 e 177; Bloch, "Apologie pour l'histoire", 971.

${ }^{9}$ Bernard, An introduction to the study of experimental medicine, 188; "Quand on crée un mot pour caractériser un phénomène, on s'entend en général à ce moment sur l'idée qu'on veut lui faire exprimer et sur la signification exacte qu' on lui donne, mais plus tard, par le progrès de la science, le sens du mot change pour les uns, tandis que pour les autres le mot reste dans le langage avec sa signification primitive. Il en résulte alors une discordance qui, souvent, est telle, que des hommes, en employant le même mot, expriment des idées très différentes. Notre langage n'est en effet qu'approximatif, et il est si peu précis, même dans les sciences, que, si l'on perd les phénomènes de vue, pour s'attacher aux mots, on est bien vite en dehors de la réalité". Bernard, Introduction à l'étude de la médecine expérimentale, 330 e 331. Bloch faz referência à introdução de Claude Bernard em “Apologie pour l'histoire”, 831, 908.
} 
Como seria muito instrutivo - seja quanto ao Deus de ontem ou hoje - se pudéssemos ouvir as verdadeiras orações nos lábios dos humildes! Supondo, é claro, que eles próprios soubessem como expressar os impulsos de seus corações sem mutilá-los. Pois aí, em última análise, está o maior obstáculo. Nada é mais difícil para nós do que a autoexpressão. [...] Os termos mais usuais nunca passam de aproximações. ${ }^{10}$

Estas palavras, baseadas na experiência de pesquisa pessoal de Bloch, não foram inspiradas pelo ceticismo - muito pelo contrário. A consciência da inadequação de qualquer palavra, escrita ou dita, sugeriu estratégias indiretas para Bloch que lhe permitiu ler fontes medievais contra a corrente. Podem-se lembrar as magníficas páginas de Les rois thaumaturges dedicadas a homens e mulheres afetados por escrófula, que percorriam distâncias enormes ansiando pelo toque milagroso da mão real. ${ }^{11}$ Mas a mesma consciência havia reforçado seu compromisso com uma história comparativa baseada, como no caso de Les rois thaumaturges, em categorias e termos inevitavelmente distantes daqueles usados nas evidências.

\section{IV}

Esses elementos vêm à tona no ensaio de 1928 intitulado "Pour une histoire comparée des sociétés européennes", uma espécie de manifesto metodológico, que ainda é um ponto de referência indispensável. ${ }^{12} \mathrm{Na}$ conclusão de seu ensaio, Bloch evocou o preconceito duradouro que identifica a história comparada com a busca de analogias, inclusive as mais superficiais. Todo o objetivo da história comparativa, Bloch insistiu, é enfatizar as diferenças específicas entre os fenômenos com os quais lida. Para tanto, é preciso deixar de lado todas as falsas semelhanças: por exemplo, no domínio da Idade Média europeia, a suposta equivalência entre a vilania inglesa e a servidão francesa. É verdade que alguns cruzamentos são inegáveis: "Servo e vilão são considerados, por juristas e pela opinião geral, como indivíduos desprovidos de 'liberdade': portanto, em alguns textos latinos, eles são rotulados de servi [...]. Assim, os homens de instrução, partindo da ausência de liberdade e da referência à servidão, foram levados a compará-los aos escravos romanos". Mas isso, de acordo com Bloch, é "uma analogia superficial: o conceito de não liberdade, no que diz respeito ao seu conteúdo, sofreu muitas variações em diferentes épocas e lugares". ${ }^{13}$

Resumindo: temos dois contextos geográficos diferentes, o inglês e o francês, e duas palavras diferentes, vilão e servo. Os juristas e eruditos medievais rotineiramente cambiavam essas duas variantes com servi, o termo para escravos romanos, uma vez que vilões, servos e servi eram considerados privados de sua liberdade. Bloch rejeitou essa conclusão como superficial, basea-

\footnotetext{
${ }^{10}$ Bloch, The historian's craft, 166 e 167 (tradução minimamente modificada no original); “Quel enseignement si - le le dieu fût-il d'hier ou d'aujourd'hui - nous réussissions à atteindre sur les lèvres des humbles leur véritable prière! A supposer, cependant, qu'il aient su, eux-mêmes, traduire, sans le mutiler, les élans de leur coeur. Car là est, en dernier ressort, le grand obstacle. Rien n'est plus difficile à un homme que de s'exprimer soi-même. [...] Les termes les plus usuels ne sont jamais que des approximations". Bloch, "Apologie pour l'histoire", 965.

${ }^{11}$ Bloch, Les rois thaumaturges, 89-157.

12 Bloch, "Pour une histoire comparée des sociétés européennes".

${ }^{13}$ Bloch, "Pour une histoire comparée des sociétés européennes", 28.
} 
do em um argumento apresentado por uma série de estudiosos, incluindo Paul Vinogradoff, o grande medievalista anglo-russo: o que significa que, por volta do ano 1300, os vilões se juntaram à categoria de "inquilinos livres" na Inglaterra; na França, no mesmo período, os arrendatários distinguiam-se nitidamente dos servos. Bloch traçou essas trajetórias históricas divergentes, concluindo: “No século XIV, o servo francês e o vilão inglês pertenciam a duas classes completamente diferentes. É útil compará-los? Certamente, mas essa comparação terminará revelando características bastante diferentes, sugerindo uma notável disjunção no desenvolvimento das duas nações". ${ }^{14}$

Aqui, como em outras passagens do mesmo ensaio, Bloch usou a palavra "classes" (classes) para identificar duas realidades sociais diferentes erroneamente fundidas por juristas medievais. Mas seu comentário sobre as normas assumidas pelos juristas ingleses, que atribuíam um grau menor de liberdade aos indivíduos que tinham que realizar pesadas tarefas agrícolas (corvées), caminhava em outra direção. "Essas normas", escreveu Bloch, "estavam longe de ser originais. Eles simplesmente contaram com uma camada de representações coletivas, elaboradas muito antes, desordenadamente, dentro das sociedades medievais tanto no continente como nas ilhas britânicas. A ideia de que o trabalho agrícola é de alguma forma intrinsecamente incompatível com a liberdade surge de antigos hábitos mentais, exemplificados pelas palavras opera servilia, aplicadas pelos bárbaros a esse tipo de trabalho". ${ }^{15}$ Abandonando o domínio da terminologia documentada, Bloch mudou abruptamente para um terreno hipotético mais escorregadio: "representações coletivas". Essa noção é retirada de Durkheim, cujo nome recebeu ênfase especial em uma nota de rodapé. Em uma passagem anterior, Bloch havia aludido a "um legado antigo e amplamente esquecido de representações populares". ${ }^{16}$

Liberdade e servidão na Idade Média, vistas em uma perspectiva cronológica mais longa, ressurgiram alguns anos depois em outro ensaio de Bloch. Em alguns casos, os termos jurídicos referentes à servidão não mudaram: mas seu significado, observou Bloch, sofreu variações imperceptíveis ao longo do tempo, como mostram os documentos carolíngios. Eles exibem uma série de deslocamentos, "obviamente inconscientes", que devem ser avaliados pelo que são: da mesma forma, os linguistas assinalaram que, em determinado momento, a palavra trabalhador (labourer) assumiu o significado da palavra latina arare, arar. ${ }^{17}$ Seguindo o exemplo dos linguistas, escreveu Bloch, os historiadores deveriam abster-se de substituir as interpretações fornecidas no passado pelas suas próprias. ${ }^{18}$

Esta é uma afirmação um tanto inesperada. Em uma passagem de seu ensaio anterior, Bloch havia rejeitado a assimilação infundada da servidão medieval à escravidão antiga, inspirada na palavra latina servi. No entanto, pode-se argumentar que reconstruir as perspectivas dos juristas e enfatizar suas limitações não são objetivos incompatíveis. Há mais. O ensaio em que Bloch exortou os historiadores a tomarem os linguistas como modelo é intitu-

\footnotetext{
${ }^{14}$ Bloch, "Pour une histoire comparée des sociétés européennes", 30.

${ }^{15}$ Bloch, "Pour une histoire comparée des sociétés européennes", 31.

${ }^{16}$ Bloch, "Pour une histoire comparée des sociétés européennes", 30, n. 1, 29, n. 2.

17 Bloch, "Liberté et servitude personnelles au Moyen Âge", esp. p. 332.

${ }^{18}$ Bloch, "Liberté et servitude personnelles au Moyen Âge", 327 e 328.
} 
lado "Liberdade pessoal e servidão pessoal na Idade Média, especialmente na França: uma contribuição para a análise das classes" ("Liberté et servitude personnelles au Moyen Âge, particulièrement en France: contribution à l'étude des classes", 1933). Para Bloch, "classe", uma categoria moderna, longe de apagar as categorias propostas pelos juristas medievais, inscreveu-as em uma perspectiva que é nossa, não deles. Este ponto é enfatizado nas passagens finais do ensaio: “Tudo nos leva à mesma conclusão. Visto que as instituições humanas são realidades de tipo psicológico, uma classe nunca existe, exceto na medida em que a percebemos. Escrever a história da servidão significa, antes de tudo, traçar, na complexa e mutante trajetória de seu desenvolvimento, a história de uma noção coletiva: a privação da liberdade" ${ }^{19}$

Desnecessário dizer que a interpretação psicológica de classe proposta por Bloch pode ser aceita, debatida ou rejeitada com base em diferentes categorias analíticas. Mas suas reflexões suscitam uma questão mais geral: qual a relação entre as categorias do observador e dos protagonistas, recuperadas de documentos medievais? Outra pergunta segue imediatamente. Os juristas medievais eram observadores e protagonistas ao mesmo tempo. Qual a relação entre a representação da servidão compartilhada pelos juristas e a representação da servidão compartilhada pelos servidores?

Esta última questão, que Bloch não levanta explicitamente, surge irresistivelmente de sua própria pesquisa. Neste ponto, devo fazer uma digressão pessoal. Ler Les rois thaumaturges em 1959, quando eu tinha vinte anos, me convenceu a tentar aprender o ofício do historiador. Poucos meses depois, decidi me comprometer com o estudo dos julgamentos de bruxaria, concentrando-me nos homens e mulheres que estavam diante dos juízes, e não na perseguição como tal. Impulsionando-me nessa direção estavam alguns livros (Cadernos do cárcere, de Antonio Gramsci, Cristo parado em Eboli, de Carlo Levi, Il mondo magico, de Ernesto de Martino), bem como memórias pungentes de perseguição racial. Mas só muitos anos depois é que me dei conta de que minha experiência como criança judia durante a guerra me levou a me identificar com os homens e mulheres acusados de bruxaria. ${ }^{20}$

Seguindo o conselho de meu mentor, Delio Cantimori, comecei a estudar os julgamentos da Inquisição (muitos deles lidando com bruxaria ou crimes relacionados) preservados no Arquivo do Estado de Modena. Então, estendi minha pesquisa para outros arquivos - uma jornada bastante errática, já que não tinha uma agenda específica. No início da década de 1960, lendo os autos do julgamento da Inquisição preservados no Arquivo do Estado de Veneza, encontrei um documento que era, como imediatamente percebi, uma anomalia completa: algumas páginas, datadas de 1591, registrando o exame

\footnotetext{
${ }^{19}$ Bloch, “Liberté et servitude personelles au Moyen Âge”, 355: “Ainsi nous nous trouvons ramenés de toutes parts à la même leçon. Les institutions humaines étant des réalités d'ordre psychologique, une classe n'existe jamais que par l'idée qu'on s'en fait. Ecrire l'histoire de la condition servile, c'est, avant tout, retracer, dans la courbe complexe et changeante de son développement, l'histoire d'une notion collective: celle de la privation de liberté". Cf. Ginzburg, "A proposito della raccolta dei saggi storici di Marc Bloch". ${ }^{20}$ Ginzburg, "Streghe e sciamani".
} 
de Menichino della Nota, um jovem pastor de Friuli. Menichino respondeu às perguntas do inquisidor dizendo que era um benandante. $\mathrm{O}$ significado desta palavra era desconhecido para mim - e para o inquisidor também, que aparentemente ouviu atônito a história do réu. Por ter nascido com uma gangue, disse Menichino, era obrigado a deixar o corpo três vezes por ano, "como fumaça", viajando com os outros benandanti para lutar "pela fé contra as bruxas" na campina de Josafat. "Quando os benandanti venceram", concluiu, "era um sinal de uma boa colheita". ${ }^{21}$

Muitos anos atrás, apresentei uma análise retrospectiva de minhas reações àquele documento que encontrei por puro acaso: o primeiro de quase cinquenta julgamentos que mais tarde descobri no Arquivo Eclesiástico de Udine. Todos eles dependem de uma palavra - benandante - que suscitou perguntas dos inquisidores; as respostas fornecidas pelos réus foram repletas de detalhes extraordinários. Os julgamentos mostram que os inquisidores logo se decidiram: os benandanti, que afirmavam que seus espíritos lutavam contra bruxas e feiticeiros, eram na verdade feiticeiros. Essas denúncias provocaram negações indignadas dos benandanti, que faziam questão de descrever sua "profissão", como a chamavam, ora com orgulho, ora como fruto de um impulso obscuro e incontornável. Mas, no final das contas, depois de cinquenta anos de investigações, aqueles que acreditavam estar lutando ao lado do bem aceitaram a imagem hostil que seus interrogadores haviam construído. Este foi o resultado de um embate cultural impregnado de violência - np caso, sobretudo simbólica. O prestígio dos inquisidores, bem como a ameaça iminente de tortura e morte na fogueira, provaram ser inelutáveis.

Em um livro que publiquei em 1966, traduzido para o inglês como The night battles, analisei os contos fornecidos pelos benandanti como um fragmento da cultura camponesa, lentamente distorcida pela imposição de estereótipos inquisitoriais. Esse argumento baseava-se nas acaloradas divergências entre réus e inquisidores sobre o real significado da palavra benandante. O que tornou a extraordinária evidência friulana tão valiosa para o historiador foi a própria falta de comunicação entre os dois lados envolvidos em um diálogo dramaticamente desigual.

Depois de uma pausa que durou muitos anos, retomei meu trabalho em julgamentos de bruxaria. Naquela época, percebi que minha abordagem sobre os juízes, tanto leigos quanto eclesiásticos, havia sido inadequada em muitos aspectos. Seu comportamento às vezes era marcado por uma tentativa genuína de dar sentido às crenças e atos dos réus - a fim de erradicá-los, é claro. A distância cultural pode gerar um esforço para compreender, comparar, traduzir. Deixe-me relembrar um caso extremo, mas esclarecedor. Em 1453, o bispo de Brixen - o filósofo Nicolau de Cusa - ouviu as histórias contadas por duas mulheres idosas de um vale próximo. Em um sermão proferido algum tempo depois, ele os descreveu como "meio malucos" (semideliras). Elas prestaram homenagem a uma deusa noturna que chamaram de "Richella" (de "ricchezza", traduzível como "riqueza"). O erudito bispo identificou Richella com Diana, Abundia, Satia: nomes mencionados nas seções das enciclo-

\footnotetext{
${ }^{21}$ Ginzburg, I benandanti, 84-87; Ginzburg, The night battles: witchcraft and agrarian cults in the sixteenth and
} seventeenth centuries, 74-77. 
pédias medievais e tratados sobre direito canônico a respeito de superstições populares. ${ }^{22}$ Essa tentativa hermenêutica não foi excepcional. Juízes e inquisidores menos ilustres redigiram resumos e traduções que, contidos em uma série de caixas chinesas aninhadas, estão à disposição do intérprete moderno no caso, eu mesmo. Com certo embaraço descobri, além de minha identificação emocional com as vítimas, uma contiguidade intelectual preocupante com os perseguidores: uma condição que procurei analisar em um ensaio intitulado "The inquisitor as anthropologist" (O inquisidor como antropólogo). ${ }^{23}$

Não consigo imaginar qual direção minha pesquisa - em primeiro lugar, a que fiz nos arquivos friulanos - teria tomado se eu nunca tivesse encontrado os escritos de Bloch. Em retrospecto, sou tentado a comparar os sonhos extáticos dos benandanti às "verdadeiras preces" dos humildes evocadas por Bloch: experiências internas que as palavras (documentadas no primeiro caso, imaginadas no último) registram de maneira inevitavelmente inadequada. No caso de benandanti, somos confrontados com palavras proferidas a mando do inquisidor, e então transcritas pelos tabeliães do inquisidor: um contexto conflituoso (embora regulamentado por lei) que deve ser levado em consideração, mas que não torna a prova menos relevante.

Estou inclinado a acreditar que nenhum historiador teria deixado escapar tal conflito tão flagrante. Muito menos óbvia, a meu ver, era a percepção, que só notei muitos anos depois, de minha contiguidade com os inquisidores. Talvez essa contiguidade tenha se imposto à minha mente apenas quando me tornei consciente das raízes profundas por trás da escolha preliminar que moldou meu projeto de pesquisa desde o início.

Identificação emocional com as vítimas, contiguidade intelectual com os inquisidores: estamos muito afastados dos elementos que, no modelo de pesquisa histórica descrito por Bloch, nos aproximam do positivismo. Em suas reflexões sobre a nomenclatura, o conflito aparece apenas do lado do protagonista: por exemplo, em suas observações sobre um fenômeno comparativamente tardio como a consciência de classe, seja dos trabalhadores do século XX, seja dos camponeses nas vésperas da Revolução Francesa. ${ }^{24}$ Mas do lado da linguagem do observador-historiador, que Bloch teria desejado conformar, tanto quanto possível, à linguagem neutra e distanciada das ciências naturais, o conflito nunca é mencionado.

Na perspectiva que estou defendendo, uma atitude crítica e imparcial pode ser uma meta, não um ponto de partida. Embora o fim não seja diferente do de Bloch, as estradas que levam a ele o são. Diante da arriscada contiguidade entre a linguagem do historiador e a linguagem da evidência, a esterilização dos instrumentos de análise é mais urgente do que nunca - especialmente nos casos que apresentam uma contiguidade entre observador e obser-

\footnotetext{
${ }^{22}$ Ginzburg, Storia notturna: una decifrazione del sabba, 70-73, 107 e 108; Ginzburg, Ecstasies: deciphering the witches's sabbath, 94-96.

${ }^{23}$ Ginzburg, "The inquisitor as anthropologist".

${ }^{24}$ Bloch, The historian's craft, 167; Bloch, "Apologie pour l'histoire", 96.
} 
vadores-protagonistas (o inquisidor como antropólogo, o inquisidor como historiador).

\section{VII}

Estas reflexões retrospectivas sobre a pesquisa que fiz nos arquivos friulanos nas décadas de 1960 e 1970 são parcialmente inspiradas por meu encontro posterior com os escritos de Kenneth L. Pike. O linguista, antropólogo e missionário americano Pike enfatizou a oposição entre dois níveis de análise, o do observador e o do protagonista, rotulados, respectivamente, como ético (da fonética) e êmico (da fonêmica). A partir da linguagem, Pike estabeleceu uma teoria unificada da estrutura do comportamento humano - o título de seu trabalho mais ambicioso, publicado pela primeira vez em três partes entre 1954 e 1960, e depois reimpresso, em uma versão revisada e estendida, em 1967.

O ponto de vista ético, explicou Pike, examina línguas e culturas em uma perspectiva comparativa; o ponto de vista êmico é "culturalmente específico, aplicado a um idioma ou cultura de cada vez". ${ }^{25}$ Mas essa oposição estática e bastante intrincada é posteriormente revisada em uma perspectiva dinâmica mais eficaz:

Apresentação preliminar versus apresentação final: portanto, os dados éticos fornecem acesso ao sistema - o ponto de partida da análise. Eles fornecem resultados provisórios, unidades provisórias. A análise ou apresentação final, entretanto, seria em unidades êmicas. Na análise total, a descrição ética inicial é gradualmente refinada e, em última instância - em princípio, mas provavelmente nunca na prática -, substituída por outra totalmente êmica. ${ }^{26}$

A maioria dos historiadores, familiarizados com as reflexões matizadas e sofisticadas de Bloch, reagiria com alguma impaciência a essas observações, considerando-as excessivamente abstratas. É verdade que Pike se dirigia não a historiadores, mas a linguistas e antropólogos. ${ }^{27}$ Há muito que esses dois grupos tratam da distinção entre os níveis êmico e ético; os historiadores, ao contrário, o ignoraram, com poucas exceções (Eu mesmo tomei conhecimento da divisão êmicalética há vinte anos, ou seja, vinte anos após a publicação da magnum opus de $\mathrm{Pike}^{28}$ ). Mas pode não ser inútil tentar uma tradução da passagem

\footnotetext{
${ }^{25}$ Um eco dessa definição está em Subrahmanyam, "Monsieur Picart e os gentios da Índia", esp. 206: etic, ou seja, "universalista" vs. emic, ou seja, "internalista".

${ }^{26}$ Pike, Kenneth L., Language in relation to a unified theory of the structure of human behavior, 37-39. A última frase desta passagem é citada (com desacordo) em Harris, Marvin. "History and significance" 329-350, que termina com uma crítica à atitude de Claude Lévi-Strauss, rotulada como "obscurantista" e inspirada pelo idealismo de Berkeley. Lévi-Strauss, cuja enorme obra Mythologiques (1964-1971) em quatro volumes tinha acabado de ser publicada, rejeitou a distinção, alegando que a ética não é nada mais que a êmica dos observadores. Lévi-Strauss, "Structuralisme et écologie", 143-166, esp. 161 e 162. Observações úteis (que estranhamente não mencionam o ensaio de Lévi-Strauss) se acham em Olivier de Sardan, Jean Pierre. "Emique", 151-166 (muito obrigado a Simona Cerutti por ter me chamado a atenção para esta peça). Minha própria discordância com Harris e, em um nível incomparavelmente mais alto, com Lévi-Strauss será exposta a seguir no texto.

${ }_{27}$ "Não sou um linguista histórico", escreveu Pike em "On the emics and etics of Pike and Harris", 40.

${ }_{28}^{8}$ [Ginzburg], "Saccheggi rituali. Premesse a una ricerca in corso". Uma exceção relevante é Simona Cerutti,

"Microhistory: social relations versus cultural models?" (veja meu comentário na nota de rodapé 31).
} 
mencionada, usando palavras associadas à pesquisa histórica. E, assim, o resultado seria: "Os historiadores partem de perguntas usando termos que são inevitavelmente anacrônicos. O processo de pesquisa modifica as questões iniciais com base em novas evidências, recuperando respostas que são articuladas na linguagem dos protagonistas e relacionadas a categorias peculiares à sua sociedade, que é totalmente diferente da nossa".

Minha tradução dos "resultados provisórios" gerados pela perspectiva ética - "Os historiadores partem de questões usando termos que são inevitavelmente anacrônicos" - ecoa uma observação feita por Bloch. ${ }^{29}$ Perguntas, não respostas: uma distinção que não foi percebida por aqueles que enfatizaram descuidadamente o papel do anacronismo na pesquisa histórica ou rejeitaram o anacronismo como uma categoria pertinente. ${ }^{30}$ Parte-se de questões éticas com o objetivo de obter respostas êmicas. ${ }^{31}$

Podemos comparar minha tradução provisória com uma das regras do decálogo que Arnaldo Momigliano propôs muitos anos atrás, intitulado "As regras do jogo no estudo da História Antiga". A regra se aplica à história de qualquer período: "Assim que entramos no campo da pesquisa histórica, o judaísmo, o cristianismo, o Islã, Marx, Weber, Jung e Braudel nos ensinam a submeter as evidências a questões específicas; eles não afetam as respostas que as evidências fornecem. A arbitrariedade do historiador desaparecerá assim que ele tiver que interpretar um documento". ${ }^{32}$

Na minha opinião, a passagem de Pike e a regra de Momigliano não diferem significativamente. $\mathrm{O}$ que considero uma divergência reside em outro lugar. O elemento ético residual que, segundo Pike, não pode ser apagado, deve ser visto em termos positivos: como um elemento intrínseco da atividade de tradução que é, etimologicamente, sinônimo de interpretação. A tensão entre nossas perguntas e as respostas que obtemos das evidências deve ser mantida viva, embora as evidências possam modificar nossas perguntas iniciais. ${ }^{33}$ Se a diferença entre nossas palavras e as deles for cuidadosamente preservada, isso nos impedirá de cair em duas armadilhas - empatia e ventriloquismo. ${ }^{34}$ De fato, eles estão relacionados: ao assumir a transparência dos protagonistas, atribuímos a eles nossa linguagem e nossas categorias. O resultado é uma distorção insidiosa, que é muito mais perigosa (por ser mais difícil de localizar) do que suposições grosseiramente anacrônicas como homo oeconomicus e semelhantes.

\footnotetext{
${ }^{29}$ Bloch, The historian's craft, 158; “Les documents tendent à imposer leur nomenclature; l'historien, s'il les écoute, écrit sous la dictée d'une époque chaque fois différente. Mais il pense, d'autre part, naturellement selon les catégories de son propre temps... “. Bloch, “Apologie pour l'histoire”, 959 e 960.

${ }^{30}$ Ver, respectivamente, Loraux, "Eloge de l'anachronisme en histoire"; Didi-Huberman, Devant le temps: histoire de l'art et anachronisme des images; Rancière, "Le concept d'anachronisme et la vérité de l'historien", 53-68.

31 "Êmico é um método de análise, não o contexto imediato do comportamento", escreveu S. Cerutti, criticando minha própria abordagem (Cerutti, "Microhistory", 35; itálico no texto). Mas, a meu ver, a perspectiva êmica só pode ser apreendida por meio da mediação de uma perspectiva ética: daí o papel ativo (que Cerutti considera arbitrário: ibid., 34), desempenhado pelo pesquisador no processo de pesquisa.

32 Momigliano, "Le regole del gioco nello studio della storia antica", 483.

${ }^{33}$ Curiosamente, a revisão das questões iniciais está faltando na versão de Clifford Geertz do círculo hermenêutico. Ver Geertz, “'Do ponto de vista do nativo': sobre a natureza do entendimento antropológico".

${ }^{34}$ Só depois de ter escrito estas páginas percebi que a mesma metáfora foi usada em Daston e Galison, Objetividade, 257: "ventriloquizar a natureza" (mas todo o contexto é relevante).
} 
A palavra latina interpres nos lembra que qualquer interpretação é uma tradução e vice-versa. A tradução vem à tona nos debates inspirados nos argumentos de Pike. Um grupo de reações foi publicado em um livro intitulado Emics and etics: the insider/ outsider debate, baseado em uma conferência realizada em Phoenix em 1988. Um dos participantes, Willard Quine, o filósofo famoso por suas reflexões sobre a "tradução radical", terminou sua palestra da seguinte forma: "E ainda permanece, entre o exterior e o interior, uma assimetria vital. Nosso compromisso provisório, mas responsável com nossa ciência, se estende ao que dizemos sobre a cultura exótica, e não se estende ao que os pertencentes a essa cultura dizem dentro dela". ${ }^{35}$

A assimetria entre nossas palavras e as deles, enfatizada por Quine (e por Pike antes dele), também foi experimentada por historiadores: como diz o ditado, "o passado é um país estrangeiro". ${ }^{36}$ Afinal, não é surpreendente que tal assimetria tenha sido articulada e teorizada por um antropólogo. A distância, tanto linguística quanto cultural, que costuma separar os antropólogos dos ditos "nativos" impede que aqueles presumam, como tantas vezes fazem os historiadores, que se tornaram íntimos dos personagens com os quais lidam. Como mencionei antes, o ventriloquismo é uma doença profissional à qual muitos historiadores sucumbem. Mas nem todos eles, obviamente.

Alguém certa vez falou de uma antropologia êmica, especificamente comprometida em resgatar "o ponto de vista do nativo", como disse Malinowski. ${ }^{37}$ Por analogia, pode-se falar de uma historiografia êmica. Três exemplos esplêndidos serão suficientes: os ensaios de Paul Oskar Kristeller e Augusto Campana sobre as origens da palavra "humanista" e a palestra pouco conhecida de Ernst Gombrich sobre o Renascimento como período e como movimento. ${ }^{38}$ Todas as três tentativas de reconstruir as categorias dos protagonistas como distintas das categorias dos observadores - as últimas categorias muitas vezes informam o pensamento de um grupo que se estende muito além do círculo de historiadores profissionais. No final de seu ensaio, Campana observou que recentemente (isso foi escrito em 1946) alguém havia falado de "um novo humanismo: e a palavra antiga está impregnada de novos ideais. Futuros filólogos e historiadores vão lidar com eles". Mas em um pós-escrito publicado no ano seguinte, Campana usou palavras mais fortes: ele acreditava que Kristeller, no ensaio que havia escrito independentemente sobre o mesmo assunto, havia demonstrado que o conceito moderno de "humanismo renascentista [...] é insustentável". ${ }^{39}$ Insustentável, é claro, do ponto de vista filológico. Isso não nos impede de usar categorias como "Renascença" (como o próprio Campana o fez posteriormente). ${ }^{40}$ Mas devemos sempre estar cientes de que, por mais úteis que sejam, esses rótulos permanecem convencionais. Aqueles que se esforçam para descobrir as características intrínsecas do hu-

\footnotetext{
${ }^{35}$ Quine, “The phoneme's long shadow", 167.

36 Lowenthal, The past is a foreign country.

${ }^{37}$ Feleppa, "Emic analysis and the limits of cognitive diversity", $101 \mathrm{f}$.

${ }^{38}$ Kristeller, "Humanism and scholasticism in the Italian Renaissance" (ver também introdução, XI - XII); Campana, "A origem da palavra 'humanista'"; Dionisotti, "Ancora humanista-umanista"; Gombrich, "The Renaissance: period or movement"

${ }^{39}$ Campana, "The origin of the word 'humanist'", 280 e 281.

${ }^{40}$ Campana, "The origin of the word 'humanist"”, 405.
} 
manismo, da Renascença, da modernidade, do século XX, estão - para dizer o mínimo - perdendo tempo.

\section{VIII}

A dimensão êmica que eu propus, a título de experiência, encontrar na historiografia pode ser descrita usando palavras mais antigas e familiares: filologia, antiquarismo (a antropologia nasceu do antiquarianismo, então o círculo se fechou). Mas uma transferência mecânica da oposição entre êmica e ética para o discurso historiográfico seria enganosa. Baseando-se em sua própria prática, os historiadores podem apontar que a dicotomia êmicalética é um tanto simplista. Como mostra meu caso friulano, tanto a dimensão êmica quanto a ética são teatros de conflitos: entre inquisidores e benandanti (no primeiro caso), entre estudiosos de orientações variadas (no último). Mas tomar consciência da distinção êmicalética pode ajudar os historiadores a se libertarem de um viés etnocêntrico: uma tarefa que se torna mais urgente em um mundo moldado pela globalização - um processo que já dura séculos, mas que assumiu um ritmo verdadeiramente frenético nas últimas décadas.

Os historiadores devem enfrentar esse desafio - mas a questão é como? Uma resposta foi oferecida por debates sobre textos literários. Pode-se começar com "Philology of world literature [Weltliteratur]", de Erich Auerbach, um ensaio famoso que apareceu em 1952 e que hoje tem um toque quase profético. ${ }^{41}$

Uma profecia sombria. No meio da Guerra Fria, Auerbach viu uma tendência generalizada à homogeneidade cultural: um fenômeno que, apesar das diferenças óbvias, afetou os dois blocos. O mundo estava se tornando mais parecido; mesmo os Estados-nação, que no passado foram agentes de diferenciação cultural, perderam parte de seu poder. A cultura de massa (um termo que Auerbach não usou: mas essa foi a essência de sua análise) estava se espalhando por toda a superfície do globo. Estava surgindo uma Weltliteratur, em um contexto completamente diferente daquele imaginado por Goethe: uma literatura mundial em que a Europa tinha um papel marginal. Diante dessa enorme expansão no espaço e no tempo, até mesmo um grande estudioso como Auerbach percebeu a inadequação de seus instrumentos. Por isso, ele deu alguns conselhos a jovens estudiosos da literatura, tanto negativos quanto positivos. Por um lado, sugeriu que eles deveriam evitar tanto conceitos gerais como Renascença ou barroco quanto uma abordagem monográfica baseada na obra de um único autor. Por outro, recomendou que procurassem detalhes específicos que pudessem servir como pontos de conexão (Ansatzpunkte).

Auerbach estava se referindo ao método que inspirou seu grande livro, Mimesis. Mas, em 1952, as reflexões que ele apresentara menos de uma década antes, na seção final de Mimesis, foram desenvolvidas em uma direção diferente. Se a relevância da tradição literária europeia não podia mais ser tomada como certa, a questão da generalização passou a ocupar o primeiro plano, em-

\footnotetext{
${ }^{41}$ Auerbach, "Philologie der Weltliteratur". Ver também a introdução: Salvaneschi and Endrighi, "La letteratura cosmopolita di Erich Auerbach".
} 
bora de forma implícita. Generalização - mas começando de onde e com que propósito?

Há alguns anos, em um ensaio intitulado "Conjecturas sobre a literatura mundial" (que curiosamente não menciona Auerbach), Franco Moretti abordou corajosamente essas questões. ${ }^{42}$ Diante do desafio proporcionado por um enorme número de textos que nenhum estudioso da literatura comparada poderia dominar, Moretti sugeriu uma solução drástica: a leitura de segunda mão. Os estudiosos comprometidos com uma abordagem comparativa da literatura levantariam questões gerais ao absorver as percepções de estudiosos que haviam trabalhado em uma perspectiva mais circunscrita, devotada a uma literatura nacional específica. Portanto, o estudo comparativo da literatura seria baseado não na leitura atenta, mas na leitura a distância. Esta proposta, apresentada em um tom deliberadamente provocativo, foi enquadrada por um argumento baseado no ensaio de Marc Bloch "Para uma história comparada das sociedades europeias". Uma comparação entre as duas passagens relevantes - primeiro de Moretti, depois, na tradução, de Bloch - será útil. Aqui está Moretti:

Escrevendo sobre história social comparada, Marc Bloch uma vez cunhou um adorável "slogan", como ele próprio o chamou: "anos de análise por um dia de síntese"; e, se você ler Braudel ou Wallerstein, verá imediatamente o que Bloch tinha em mente. O texto que é estritamente de Wallerstein, seu "dia de síntese", ocupa um terço de uma página, um quarto, talvez metade; o resto são citações (quatrocentas, no primeiro volume de The modern world-system). Anos de análise; a análise de outras pessoas, que a página de Wallerstein sintetiza em um sistema.43

"O velho ditado é sempre verdadeiro: anos de análise por um dia de síntese", escreveu Bloch. Ele estava se referindo a uma passagem da introdução de Fustel de Coulanges ao seu La Gaule romaine, publicado em 1875. Em uma nota de rodapé, Bloch forneceu a citação exata: "Para um dia de síntese, anos de análise são necessários". Nenhuma reavaliação do inventor do ditado é tão importante quanto o comentário subsequente de Bloch: "Muitas vezes, este ditado foi citado sem adicionar sua correção indispensável: a 'análise' pode ser usada para a 'síntese' apenas se levar em conta esta última e tentar se colocar a seu serviço desde o início”. ${ }^{4}$

A qualificação de Bloch aponta na direção oposta à leitura de Moretti. ${ }^{45}$ Não se deve, como pensam os positivistas, acumular tijolos, isto é, pesquisa monográfica, para um edifício que só existe na mente do arquiteto (ou do professor de literatura comparada). As evidências devem ser coletadas de acordo com uma agenda que já aponta para uma abordagem sintética. Em outras palavras, é preciso resolver os casos, o que levará a generalizações. Mas, como a maioria das evidências foi coletada, filtrada ou abordada por estudiosos anteriores, que partiram de questões diferentes das nossas, a história da historio-

\footnotetext{
${ }^{42}$ Moretti, “Conjectures on world literature". Arac, “Anglo-globalism?" sugere uma leitura paralela dos ensaios de Moretti e Auerbach.

${ }^{43}$ Moretti, "Conjectures on world literature", 56 e 57.

${ }^{44}$ Bloch, "Pour une histoire comparée des sociétés européennes", 38.

${ }^{45}$ A passagem de Bloch é citada em primeira mão (sem a qualificação que se segue imediatamente) em Moretti, Il romanzo di formazione, "Prefazione 1999".
} 
grafia deve ser incorporada à pesquisa histórica. Quanto maior for a nossa distância da evidência primária, maior será o risco de sermos apanhados por hipóteses apresentadas por intermediários ou por nós próprios. Em outras palavras, corremos o risco de encontrar o que procuramos - e nada mais.

Essa leitura distorcida da passagem de Bloch é especialmente surpreendente, já que o próprio Moretti, em um ensaio brilhante, publicado simultaneamente com "Conjectures on world literature", mostra que a única maneira de enfrentar o desafio decorrente da enorme e intransponível massa de publicações e textos esquecidos, é trabalhar um estudo de caso: uma análise em primeira mão de uma série limitada de textos, identificados por meio de uma questão específica. Esse segundo ensaio, intitulado “O matadouro da Literatura" (alusão a um aforismo de Hegel), trata de um artifício literário que Conan Doyle colocou, quase sem querer, no cerne de suas histórias de detetive: as pistas. ${ }^{46}$ Muitos anos atrás, escrevi um ensaio intitulado "Pistas" que trata de Sherlock Holmes e outros tópicos de uma perspectiva bem diferente. ${ }^{47}$

Se não me engano, ambos os ensaios, o de Franco Moretti e o meu, implicam o dispositivo conhecido como mise en abyme: uma vez que as pistas, enquanto tópico, são analisadas por meio de uma abordagem baseada em pistas, os detalhes replicam o todo. ${ }^{48}$ Mas as pistas exigem uma leitura em primeira mão: o responsável pela síntese final não pode delegar essa tarefa a outros. Além disso, uma leitura atenta e analítica é compatível com uma enorme quantidade de evidências. Quem está familiarizado com a pesquisa arquivística sabe que é possível continuar folheando inúmeros registros documentais e inspecionar rapidamente o conteúdo de inúmeras caixas antes de parar repentinamente, detido por um documento que poderia ser examinado por anos. $\mathrm{Da}$ mesma forma, uma galinha (espero que ninguém se incomode com tal comparação) anda para a frente e para trás, olhando ao redor, antes de agarrar abruptamente uma minhoca até então escondida no chão. Mais uma vez, voltamos ao Ansatzpunkte: os pontos específicos que, como Auerbach argumentou, podem fornecer as sementes para um programa de pesquisa detalhado com um potencial generalizante - em outras palavras, um caso. Os casos anômalos são especialmente promissores, uma vez que as anomalias, como Kierkegaard certa vez observou, são mais ricas, do ponto de vista cognitivo, do que as normas, na medida em que as primeiras invariavelmente incluem as últimas mas não o contrário. ${ }^{49}$

IX

Por um certo número de anos os casos têm sido objeto de crescente atenção, parcialmente relacionados aos debates em curso sobre micro-história: um termo cujo prefixo - micro - alude, como tem sido repetidamente enfatizado (mas nunca o suficiente, talvez) ao microscópio, ao olhar analítico, não

\footnotetext{
46 Moretti, “The slaughterhouse of Literature”.

${ }^{47}$ Ginzburg, "Spie: radici di un paradigma indiziario"; Ginzburg, "Clues: roots of an indiciary paradigm".

${ }^{48}$ Dällenbach, Le récit spéculaire: essai sur la mise en abyme.

${ }^{49}$ Cf. Schmitt, Politische Theologie: Vier Kapitel zur Lehre von der Souveränität, 33, referindo-se a um "teólogo protestano" não identificado. Agradeço muito a Henrique Espada Lima, que me fez conhecer a origem desta observação, que eu inadvertidamente fiz minha.
} 
para as dimensões, alegadas ou reais, do objeto sob escrutínio. ${ }^{50}$ No entanto, a micro-história, baseada em pesquisa analítica (e, portanto, de primeira mão), visa à generalização: uma palavra que geralmente é, e erroneamente, tomada como certa. Uma reflexão mais aprofundada é necessária para explorar a ampla gama de suas variedades, com base em diferentes pontos de partida (perguntas ou respostas), diferentes tipos de analogia (metonímica, metafórica) e assim por diante. ${ }^{51}$

Pode-se objetar que, em um mundo globalizado, não há espaço para a micro-história. Eu argumentaria o oposto. A recepção internacional da microhistória pode ser facilmente interpretada de uma perspectiva política. A primeira onda de interesse pela micro-história, após seu nascimento na Itália, manifestou-se na Alemanha, França, Inglaterra, Estados Unidos. Ela foi seguida por uma segunda onda, relacionada às periferias ou semiperiferias: Finlândia, Coreia do Sul, Islândia. ${ }^{52}$ A micro-história ofereceu uma oportunidade para subverter hierarquias preexistentes, graças à relevância intrínseca - demonstrada a posteriori - do objeto sob escrutínio. Isso é completamente diferente do que foi rotulado de "anglo-globalismo": o privilégio involuntariamente imperialista de estudos em literatura comparada escrita em inglês, com base em estudos escritos em sua maioria em inglês, lidando com textos literários em sua maioria escritos em outras línguas além do inglês. ${ }^{53}$

Apoiar-se na micro-história para subverter as hierarquias políticas e historiográficas afunda suas raízes no passado distante. Não é a Tribo $X$ que é relevante, Malinowski disse uma vez, mas as questões dirigidas à Tribo X. Com um espírito semelhante, Marc Bloch argumentou que a história local deve ser tratada por meio de questões com implicações gerais. À luz do que disse até agora, a convergência entre antropologia e história parecerá óbvia. Em um mundo como o nosso, em que alguns historiadores, reagindo contra a pseudo-universalidade do Homo religiosus de Mircea Eliade, enfatizaram a dimensão etnocêntrica romana e cristã da palavra "religião", estudos de caso relacionados a contextos específicos parecem promissores, pois permitem novas generalizações, gerando novas questões e novas pesquisas. ${ }^{54}$ As respostas êmicas geram questões éticas e vice-versa.

Não quis encerrar minhas reflexões cantando louvores à microhistória. Não estou interessado em rótulos; micro-história ruim é história ruim. Nenhum método pode nos proteger de nossas limitações e erros. Quan-

\footnotetext{
${ }^{50}$ A melhor introdução ao assunto ainda é o capítulo "Kasus", em Jolles, Einfache Formen. Ver também Forrester, "If $\mathrm{p}$, then what? Thinking in cases"; Passeron e Revel (eds.), Penser par cas.

${ }^{51}$ Jakobson, "Due aspetti del linguaggio e due tipi di afasia". Muita ajuda virá de Melandri, La linea e il circolo: studio logico-filosofico sull'analogia.

52 Algumas referências bibliográficas: Chasob (ed.), Mishisa ran muoshinga; Ginzburg, Ólafsson and Magnússon, Molar og mygla: um einsögu og glataðan tíma; Magnússon, "The singularization of history: social history and microhistory within the postmodern state of knowledge"; Muir and Ruggiero (eds.), Microhistory and the lost people of Europe; Peltonen, "Carlo Ginzburg and the new microhistory"; Peltonen, "Clues, margins, and monads: the micro-macro link in historical research"; Revel (ed.), Jeux d'échelles: la micro-analyse à l'expérience.

53 Esta crítica foi levantada por Arac, "Anglo-globalismo?" Em sua resposta, Moretti não aborda essa questão: cf. Moretti, "More conjectures", (a nota 8 trata da linguagem usada pelos críticos, não da abordagem de segunda ou terceira mão a textos traduzidos supostamente realizados pelo metacrítico trabalhando em uma perspectiva comparativa).

${ }^{54}$ Momigliano, "Questioni di metodologia della storia delle religioni"; Smith, Relating religion: essays in the study of religion.
} 
do falamos à próxima geração, devemos ser francos em admitir nossas deficiências, ao mesmo tempo em que descrevemos o que, contra todas as probabilidades, temos tentado fazer. A próxima geração nos ouvirá e fará algo diferente, como sempre aconteceu. "Tristo è lo discepolo che non avanza il suo maestro" ("Pobre é o aluno que não supera seu mestre"), disse Leonardo.

\section{Bibliografia}

Arac, Jonathan. Anglo-globalism? New Left Review, 16, july-august, 2002, 35-45.

Auerbach, Erich. Philologie der Weltliteratur. In: Eric Suerbach. Gesammelte Aufsätze zur romanischen Philologie, 301-310. Bern: Francke, 1962.

Bernard, Claude. An introduction to the study of experimental medicine. New York: Macmillan, 1927; trad. H. Copley Greene; original em francês: Introduction à l'étude de la médecine expérimentale. Paris: J. B. Baillière et Fils, 1865.

Bloch, Marc. The historian's craft (with a foreword by Joseph R. Strayer). Manchester: Manchester University Press, 1984; trad. Peter Putnam; original em francês: Apologie pour l'histoire ou métier d'historien. In: Bloch, Marc. L'histoire, la guerre, la résistance (édition établie par Annette Becker et Etienne Bloch). Paris: Gallimard, 2006.

Bloch, Marc. Les rois thaumaturges (préface de Jacques Le Goff). Paris: Gallimard, 1983.

Bloch, Marc. Pour une histoire comparée des sociétés européennes. Mélanges historiques, I (ed. Ch.-E. Perrin), 16-40, Paris, S.E.V.P.E.N., 1963.

Bloch, Marc. Liberté et servitude personnelles au Moyen Âge, particulièrement em France: contribution à l'étude des classes [1933]. Mélanges historiques, I (ed. Ch.-E. Perrin), 286-355, Paris, S.E.V.P.E.N., 1963.

Campana, Augusto. The origin of the word "humanist" [1946]. In: Scritti, I, ricerche medievali e umanistiche (eds.: Rino Avesani, Michele Feo \& Enzo Pruccoli), 263-281. Roma: Edizioni di Storia e Letteratura, 2008.

Cerutti, Simona. Microhistory: social relations versus cultural models? In: Between sociology and history: essays on microhistory, collective action, and nation-building (eds. Anna-Maija Castrén, Markku Lonkila, \& Matti Peltonen), 17-40. Helsinki: SKS/Finnish Literature Society, 2004.

Chasob, Kwak (ed.) Mishisa ran muoshinga [Che cosa è la microstoria?]. Seoul: Purun Yoksa, 2000.

Ciafaloni, F. Le domande di Vittorio: un ricordo di Vittorio Foa. Una città, 176, luglioagosto, 2010, 42-43.

Dällenbach, Lucien. Le récit spéculaire: essai sur la mise en abyme. Paris: Seuil, 1977.

Daston, L. and P. Galison. Objectivity. New York: Zone Books, 2007.

Didi-Huberman, Georges. Devant le temps: histoire de l'art et anachronisme des images. Paris: Les ëditions de Minit, 2000. 
Dionisotti, Carlo. Ancora humanista-umanista. In: Scritti di storia dela letteratura italiana, III - 1972-1998 (eds. Tania Basile, Vicenzo Fera \& Susanna Villari), 365-370. Roma: Edizioni di Storia e Letteratura, 2010.

Feleppa, Robert. Emic analysis and the limits of cognitive diversity. In: Emics and etics: the insider/outsider debate. Frontiers of Anthropology, 7 (eds. Thomas N. Headland, Kenneth L. Pike \& Marvin Harris), 100-119. Newbury Park: Sage, 1990.

Freedberg, David. The eye of the Lynx: Galileo, his friends, and the beginnings of Modern Natural History. Chicago: Chicago University Press, 2002.

Forrester, J. If p, then what? Thinking in cases. History of the Human Sciences, 9, 1996, $1-25$.

Galilei, Galileo. Il Saggiatore (ed. Libero Sosio). Milano: Feltrinelli, 1965.

Geertz, Clifford. "From the native's point of view": on the nature of anthropological understanding [1974]. In: Local knowledge: further essays in interpretive anthropology, 55-70. New York: Basic Books, 1983.

Ginzburg, Carlo. Spie: radici di un paradigma indiziario. In: Miti, emblemi, spie: morfologia e storia. Torino: Einaudi, 1986. Edição em inglês: Clues: roots of an evidential paradigma. In: Carlo Ginzburg. Clues, myths, and the historical method. London and Baltimore: Johns Hopkins University Press, 1989.

Ginzburg, Carlo. Spuren einer Paradigmengabelung: Machiavelli, Galilei und die Zensur der Gegenreformation. In: Spur: Spurenlesen als Orientierungstechnik und Wissenskunst (ed. Sybille Krämer, Werner Kogge \& Gernot Grube). Frank-furt am Main: Suhrkamp Verlag, 2007.

Ginzburg, Carlo. A proposito della raccolta dei saggi storici di Marc Bloch. Studi medievali, VI, 3, 1965, 335-353.

Ginzburg, Carlo. Streghe e sciamani [1993]. In: Il filo e le tracce: vero, falso, finto, 281293. Milano: Feltrinelli, 2006.

Ginzburg, Carlo. I benandanti. Torino: Giulio Einaudi editore, 1966; tradução em inglês: The night battles: witchcraft and agrarian cults in the sixteenth and seventeenth centuries. London: Routledge, 1983; trad. John and Anne Tedeschi.

Ginzburg, Carlo. Storia notturna: una decifrazione del sabba. Torino: Einaudi, 1989; tradução em inglês: Ecstasies: deciphering the witches' sabbath. London: Hutchinson Radius, 1990; trad. Raymond Rosenthal.

Ginzburg, Carlo. The inquisitor as anthropologist. In: Carlo Ginzburg. Clues, myths, and the historical method, 156-164. London and Baltimore: Johns Hopkins University Press, 1989.

Ginzburg, Carlo. Saccheggi rituali. Premesse a una ricerca in corso (seminário bolonhês coordenado por Carlo Ginzburg). Quaderni storici, 65, 1987, 615-636.

Ginzburg, Carlo, David Ólafsson and Sygurdur G. Magnússon. Molar og mygla: um einsögu og glataðan tíma (eds. Ólafur Rastrick and Valdimar Tr. Hafstein, Reykiavík): Bjartur-ReykjavíkurAkademían, 2000. 
Gombrich, Ernst H. The Renaissance: period or movement. In: Background to the English Renaissance: introductory lectures (ed. Joseph B. Trapp), 9-30. London: Gray-Mills Publishing, 1974.

Harris, Marvin. History and significance of the emic/etic distinction. Annual Review of Anthropology, 5, 1976, 329-350.

Jakobson, Roman. Due aspetti del linguaggio e due tipi di afasia. In: Roman Jakobson. Saggi di linguistica generale (ed. Luigi Heilmann), 22-45. Milano: Feltrinelli, 1966.

Jolles, Andrë. Einfache Formen. Halle, 1930.

Kristeller, Paul O. Humanism and scholasticism in the Italian Renaissance [1944-1945]. In: Studies in Renaissance thought and letters, 553-583. Roma: Edizioni di Storia e Letteratura, 1956.

Lëvi-Strauss, Claude. Structuralisme et e̋cologie [1972]. In: Claude Lëvi-Strauss. Le regard éloigné, 143-166. Paris: Plon, 1983.

Loraux, Nicole. Eloge de l'anachronisme en histoire. In: Le genre humain: "l'ancien et le nouveau", giugno 1993, 23-39.

Lowenthal, David. The past is a foreign country. Cambridge: Cambridge University Press, 1985.

Magnússon, Sygurdur G. The singularization of history: social history and micro-history within the postmodern state of knowledge. Journal of Social History, 36, 3, 2003, 701-735.

Melandri, Enzo. La linea e il circolo: studio logico-filosofico sull'analogia. 2. Edition. Introd. Giorgio Agamben. Apêndice por Stefano Besoli e Renzo Brigati. Macerata: Quodlibet, 2004 [1968].

Momigliano, Arnaldo. Questioni di metodologia della storia delle religioni. In: Ottavo contributo alla storia degli studi classici e del mondo antico, 402-407. Roma: Edizioni di Storia e Letteratura, 1987.

Momigliano, Arnaldo. Le regole del gioco nello studio della storia antica [1974]. In: Sui fondamenti della storia antica. Torino: Einaudi, 1984.

Moretti, Franco. Il romanzo di formazione. Torino: Einaudi, 1999.

Moretti, Franco. Conjectures on world literature. New Left Review, New Series 1, january-february, 2000, 54-68.

Moretti, Franco. The slaughterhouse of literature. Modern Language Quarterly, 61, 2000, 207-227.

Moretti, Franco. More conjectures. New Left Review, 20, march-april, 2003, 73-81.

Muir, Edwin and Guido Ruggiero (eds). Microhistory and the lost people of Europe. Baltimore: Johns Hopkins University Press, 1991. 
Passeron, Jean-Claude and Jacques Revel (eds.). Penser par cas. Paris: École des Hautes Études en Sciences Sociales, 2005.

Peltonen, Matti. Carlo Ginzburg and the new microhistory. Suomen Antropologi-Antropologi i Finland, 20, 1995, 2-11.

Peltonen, Matti. Clues, margins, and monads: the micro-macro link in historical research. History and Theory, 40, 3, 2001, 347-359.

Pike, Kenneth L. On the emics and etics of Pike and Harris. In: Emics and etics: the insider/outsider debate (eds. Thomas N. Headland, Kenneth L. Pike \& Marvin Harris). Newbury Park: Sage, 1990.

Pike, Kenneth L. Language in relation to a unified theory of the structure of human behavior. 2. revised edition. The Hague: Mouton, 1967.

Pomata, Gianna and Nancy G. Siraisi (eds.). Historia: empiricism and erudition. In: Early Modern Europe. Cambridge, Mass.: Harvard University Press, 2005.

Quine, W. V. The phoneme's long shadow. In: Emics and etics: the insider/outsider debate. Frontiers of Anthropology, 7 (eds. Thomas N. Headland, Kenneth L. Pike \& Marvin Harris), 164-167. Newbury Park: Sage, 1990.

Rancière, Jacques. Le concept d'anachronisme et la vêritë de l'historien. L'inactuel, 6, 1996, 53-68.

Revel, Jacques (ed.). Jeux d'échelles: la micro-analyse à l'expérience. Paris: GallimardSeuil, 1996.

Salvaneschi, Enrica and Silvio Endrighi. La letteratura cosmopolita di Erich Auerbach. In: Philologie der Weltliteratur - Filologia della letteratura mondiale. Castel Maggiore (Bo): Book, 2006; trad. Regina Engelmann.

Olivier de Sardan, Jean Pierre. Emique. L'homme, 147, 1998, 151-166.

Smith, Jonathan K. Relating religion: essays in the study of religion. Chicago: Chicago University Press, 2004.

Schmitt, Carl. Politische Theologie: Vier Kapitel zur Lehre von der Souveränität, Zweite Ausgabe. München and Leipzig: Dunckler \& Humblot, 1934.

Subrahmanyam, Sanjay. Monsieur Picart and the Gentiles of India. In: Bernard Picart and the first global vision of religion (eds. Lynn Hunt, Margaret Jacob \& Wijnand Mijnhardt), 197-214. Los Angeles: The Getty Research Institute, 2010.

Tradução autorizada pelo autor.

Texto recebido em 30 de outubro de 2020. Aprovado em 10 de novembro de 2020. 